\title{
Shape variation and modularity of skull and teeth in domesticated horses and wild equids
}

\author{
Laura Heck $^{1 *}$ (D), Laura A. B. Wilson², Allowen Evin ${ }^{3,4}$, Madlen Stange ${ }^{1}$ and Marcelo R. Sánchez-Villagra ${ }^{1}$
}

\begin{abstract}
Background: In horses, the morphological changes induced by the process of domestication are reportedly less pronounced than in other species, such as dogs or pigs - although the horses' disparity has rarely been empirically tested. We investigated shape differences and modularity of domesticated horses, Przewalski's horses, donkeys and zebras. Mandibular and tooth shape have been shown to be valuable features for differentiating wild and domesticated forms in some mammals.

Results: Both mandible and teeth, show a pattern of shape space occupation analogous to that of the cranium, with domesticated horses occupying a similar extension in shape space to that of wild equids. Only cranial shape data exhibit a tendency to separate domesticated horses and Przewalski's horses from donkeys and zebras. Maximum likelihood model-based tests confirm the horse cranium is composed of six developmental modules, as reported for placental mammals in general. The magnitude of integration in domesticated horse skull was lower than in wild equids across all six cranial modules, and lower values of integration were associated with higher disparity values across all modules.
\end{abstract}

Conclusion: This is the first study that combines different skeletal features for the description and comparison of shape changes in all living equid groups using geometric morphometrics. We support Darwin's hypothesis that the shape variation in the skull of domesticated horses is similar to the shape variation of all wild equid species existing today. Lower magnitudes of module integration are recovered in domesticated horses compared to their wild relatives.

Keywords: Domestication, Disparity, Modularity, Geometric morphometrics, Cranium

\section{Background}

After being on the verge of extinction, domestication made horses one of today's most common large animal species [1]. All living species of equids belong to the genus Equus, which is divided into the caballine taxa, including domesticated horses $(\mathrm{H})$ and Przewalski's horses $(\mathrm{P})$, and non-caballine taxa, comprising the different donkey (D) and zebra species (Z). Within the caballine taxa, the Przewalski's horses likely represent the sistertaxon to the extinct wild ancestor of domesticated horses [2, 3]. Since the early domestication of horses, reproductive isolation promoted divergence by genetic drift and natural selection. Later on, extensive selective

\footnotetext{
* Correspondence: Laura.Heck@gmx.de

'Palaeontological Institute and Museum, University of Zurich, 8006 Zurich, Switzerland

Full list of author information is available at the end of the article
}

breeding to meet human needs for certain behavioural or physiological traits resulted in a wide range of morphological variation [4-6]. Horses, like other domesticated species, have been shaped into diverse morphological types through artificial selection to fit specific functions, such as agricultural work, racing, or leisure. Four traditional body types are recognized: draft horses, medium horses, light horses, and ponies [5, 6]. Horse disparity was already acknowledged by Charles Darwin, who noted that its intraspecific disparity is larger than the interspecific disparity of equids in general [7]. Darwin proposed that great differences among horse breeds can be found in the skull. Based on its complexity in form and origin, as well as its relation to important vital functions, the skull is the most commonly used marker of morphological variation [8]. The increase in skull shape variation following domestication has been 
found in different domesticated species such as dogs [9], cattle [10], and pigeons [11], where it has been measured using geometric morphometric methods, and quantified through comparisons of variance in shape space. In addition, potential shape changes in teeth are commonly used in zooarchaeological studies to determine the time and location of domestication [12-16]. Previous studies on skull and tooth morphology and morphometrics show the existence of intraspecific as well as interspecific shape variation in subsets of the equid clade (Table 1). However, the patterning and magnitude of variation in skull shape or tooth shape across all extant equids has so far not been examined. In order to quantify the shape variation in extant equids and to investigate the impact of domestication, we first compare domesticated horses represented by 38 different breeds and encompassing the whole size range of the species, to the extant zebra and donkey species, as well as to the Przewalski's horse (Table 2) using twoand three-dimensional geometric morphometrics to explore cranial and mandible (3D), and teeth (2D) morphometrical variation.

As a second part of this study, we examine modularity of the equid skull. The concept of modularity $[17,18]$ has attracted much attention in recent years (e.g. [19-26]), having emerged as a quantitative framework for exploring questions relating to facilitation and constraint in morphological evolution, with the goal of understanding how (and by how much) the direction in which variation is generated is biased [27-29]. Many studies have quantified patterns of modularity in the cranium using inter-trait correlations extracted from geometric morphometric data (see [30] and references therein) and, taken together, their results have supported a

Table 1 Overview of previous literature on skull and/or tooth morphology and morphometrics in extant equids

\begin{tabular}{|c|c|c|c|c|}
\hline Author & Species and/or breeds & Body part & Method & Summary \\
\hline Bennett (1980) [38] & $\begin{array}{l}\text { Equus andium, E. asinus, E. burchelli, } \\
\text { E. caballus (including E. caballus alaskae, } \\
\text { originally named E. niobrarensis alaskae } \\
\text { by Hay, 1915), E. calobatus, } \\
\text { E. conversidens, E. francisi, E. grevyi, } \\
\text { E. hatcheri, E. hemionus, E. kiang, } \\
\text { E. onager, E. occidentalis, E. quagga, } \\
\text { E. scotti, E. zebra, and Dinohippus }\end{array}$ & Skull \& teeth & $\begin{array}{l}\text { Descriptive } \\
\text { morphology }\end{array}$ & $\begin{array}{l}\text { Living species of Equus can } \\
\text { be differentiated by a number } \\
\text { of morphological characters }\end{array}$ \\
\hline Seetah et al. (2016) [14] & $\begin{array}{l}\text { Icelandic, Thoroughbred, Przewalski's } \\
\text { horses, and potentially E. ferus }\end{array}$ & Teeth & $\begin{array}{l}\text { 2D geometric } \\
\text { morphometrics }\end{array}$ & $\begin{array}{l}\text { Tooth shape of horses largely } \\
\text { resembles those of Pleistocene } \\
\text { and recent wild horses until the } \\
\text { onset of modern breeds }\end{array}$ \\
\hline Seetah et al. (2014) [48] & Icelandic and Thoroughbred horses & Teeth & $\begin{array}{l}\text { 2D geometric } \\
\text { morphometrics }\end{array}$ & $\begin{array}{l}\text { Significant differences between } \\
\text { the two horse breeds in tooth } \\
\text { shape }\end{array}$ \\
\hline Evans \& McGreevy (2006) [63] & $\begin{array}{l}\text { Thoroughbreds, Standardbreds, Ponies, } \\
\text { Arabs, Anglo-Arabs, Quarter horse, } \\
\text { Warmblood, and Appaloosa }\end{array}$ & Skull & Classic morphometrics & $\begin{array}{l}\text { No overall shape differences exist } \\
\text { but modular differences } \\
\text { (nasal vs. cranial) }\end{array}$ \\
\hline Zhu et al. (2014) [64] & $\begin{array}{l}\text { E. asinus compared to ponies from Jie } \\
\text { (1995) and Evans \& McGreevy (2006) }\end{array}$ & Skull & Classic morphometrics & $\begin{array}{l}\text { Supports the two modules from } \\
\text { Evans \& McGreevy (2006) and } \\
\text { shows that donkeys have a longer } \\
\text { nasal part }\end{array}$ \\
\hline Hanot et al. (2017) [39] & $\begin{array}{l}\text { Domestic horses (E. caballus) of various } \\
\text { breeds (i.e. racehorses, draft horses, } \\
\text { Shetland ponies, Icelandic ponies, } \\
\text { Camargue horse, Pottok, Konik), } \\
\text { Przewalski's horses (E. przewalskii), } \\
\text { domestic donkeys (E. asinus asinus) } \\
\text { and wild asses (E. a. africanus), mules } \\
\text { (E.asinus x E. caballus) and hinnies } \\
\text { (E. caballus x E. asinus) }\end{array}$ & $\begin{array}{l}\text { Skull \& } \\
\text { skeleton }\end{array}$ & $\begin{array}{l}\text { 3D geometric } \\
\text { morphometrics }\end{array}$ & $\begin{array}{l}\text { Occipital part of the skull is } \\
\text { especially discriminant among } \\
\text { species and it is possible to } \\
\text { identify domesticated equids from } \\
\text { archaeological sites }\end{array}$ \\
\hline Cucchi et al. (2017) [16] & $\begin{array}{l}\text { E. ferus caballus, E. f. przewalskii, } \\
\text { E. africanus somaliensis, E. a. asinus, } \\
\text { E. kiang, E. hemionus hemionus, E. h. khur, } \\
\text { E. h. kulan, E. grevyi, E. zebra hartmannae, } \\
\text { E. quagga quagga, E. q. burchelli, and } \\
\text { hybrids (donkey*horse) }\end{array}$ & Teeth & $\begin{array}{l}2 \mathrm{D} \text { geometric } \\
\text { morphometrics }\end{array}$ & $\begin{array}{l}\text { Enamel folding is a good } \\
\text { phylogenetic marker; strong } \\
\text { taxonomic pattern is visible in } \\
\text { enamel folding }\end{array}$ \\
\hline $\begin{array}{l}\text { Eisenmann \& Baylac (2000) } \\
\text { [65] }\end{array}$ & $\begin{array}{l}\text { E. grevyi, E. burchelli boehmi, E. zebra } \\
\text { zebra, E. asinus, E. h. kulan, E. przewalskii, } \\
\text { and E. caballus }\end{array}$ & Skull & Classic morphometrics & $\begin{array}{l}\text { Domestic horses and Przewalski's } \\
\text { horses can be differentiated }\end{array}$ \\
\hline
\end{tabular}


Table 2 Number of individuals in each group (domesticated horses (H), Przewalski's horses (P), donkeys (D), and zebras (Z)) on each cranium, mandible, and tooth; sample of domesticated horses is present by breed

\begin{tabular}{|c|c|c|c|c|c|c|c|}
\hline Group & Breed & Cranium & Mandible & U3M & U2P & L3M & L2P \\
\hline \multirow[t]{38}{*}{ Domesticated horses $(\mathrm{H})$} & Ancient breed & 2 & 1 & 4 & 3 & 1 & 1 \\
\hline & Anglo-Norman & 2 & 2 & 1 & 2 & 2 & 2 \\
\hline & Arab & 7 & 8 & 6 & 7 & 4 & 2 \\
\hline & Birkenfelder & 1 & 1 & 1 & 0 & 0 & 0 \\
\hline & Belgian Draft & 11 & 10 & 9 & 8 & 6 & 9 \\
\hline & Bosnian Pony & 1 & 0 & 0 & 0 & 0 & 0 \\
\hline & Clydesdale & 3 & 3 & 3 & 3 & 3 & 2 \\
\hline & Exmoor Pony & 1 & 1 & 1 & 1 & 1 & 1 \\
\hline & Falabella & 1 & 0 & 0 & 0 & 0 & 0 \\
\hline & Galician Farm Horse & 3 & 3 & 2 & 3 & 2 & 2 \\
\hline & Grisons (Graubünden) & 3 & 3 & 3 & 3 & 3 & 3 \\
\hline & German Riding Pony & 2 & 2 & 1 & 2 & 0 & 2 \\
\hline & Hannoverian & 2 & 3 & 2 & 3 & 1 & 1 \\
\hline & Hackney & 2 & 2 & 2 & 2 & 1 & 1 \\
\hline & Holstein & 1 & 1 & 1 & 1 & 1 & 0 \\
\hline & Hungarian & 3 & 3 & 3 & 3 & 1 & 3 \\
\hline & Huzule & 3 & 2 & 2 & 2 & 2 & 1 \\
\hline & Icelandic Horse & 16 & 18 & 17 & 18 & 12 & 16 \\
\hline & Indian Pony & 2 & 1 & 2 & 2 & 1 & 1 \\
\hline & Kladrubian & 10 & 10 & 10 & 10 & 9 & 6 \\
\hline & Konik & 1 & 1 & 0 & 1 & 0 & 0 \\
\hline & Kosarian & 1 & 1 & 1 & 1 & 0 & 1 \\
\hline & Lipizzan & 2 & 2 & 0 & 2 & 0 & 2 \\
\hline & Mongolian & 3 & 3 & 3 & 1 & 2 & 1 \\
\hline & Norik & 2 & 2 & 2 & 1 & 1 & 0 \\
\hline & Oldenburgian & 1 & 1 & 1 & 1 & 1 & 1 \\
\hline & Pinzgau & 18 & 17 & 16 & 17 & 15 & 9 \\
\hline & Polish Farm Horse & 1 & 1 & 1 & 1 & 1 & 1 \\
\hline & Scottish Pony & 2 & 1 & 1 & 1 & 0 & 0 \\
\hline & Seneca Sarajevo & 1 & 0 & 1 & 1 & 0 & 0 \\
\hline & Shetland Pony & 6 & 6 & 5 & 5 & 4 & 5 \\
\hline & Shire & 1 & 1 & 1 & 1 & 1 & 0 \\
\hline & Styrian & 1 & 1 & 1 & 1 & 1 & 0 \\
\hline & Suffolk & 2 & 2 & 1 & 2 & 1 & 1 \\
\hline & English Thoroughbred & 6 & 7 & 6 & 7 & 6 & 5 \\
\hline & Togo Pony & 0 & 5 & 4 & 4 & 2 & 3 \\
\hline & Trakehner & 3 & 4 & 4 & 4 & 3 & 4 \\
\hline & Welsh & 6 & 12 & 4 & 6 & 4 & 7 \\
\hline \multicolumn{2}{|l|}{ Subtotal } & 133 & 141 & 122 & 130 & 92 & 93 \\
\hline \multicolumn{2}{|l|}{ Donkeys (D) } & 31 & 33 & 25 & 24 & 20 & 18 \\
\hline \multicolumn{2}{|l|}{ Zebras (Z) } & 47 & 48 & 42 & 41 & 29 & 28 \\
\hline \multirow[t]{2}{*}{ Przewalski's Horses (P) } & & 5 & 2 & 3 & 3 & 3 & 2 \\
\hline & Total & 216 & 224 & 192 & 198 & 144 & 141 \\
\hline
\end{tabular}


common pattern in therian mammals, with some variability in the magnitude of integration among species (e.g. $[20,31])$. In contrast, comparatively little is known about the lability of modular patterning and integration magnitudes on relatively short time scales and under selective breeding regimes, although changes in magnitude, rather than patterning, have been implicated as the target for selection [32]. Providing examples of selective breeding for features to suit human activities, the study of domestication events offers an opportunity to empirically examine the role of modularity and integration in the generation of cranial disparity over short evolutionary timescales. A modular structure of the skull is expected to be uncovered for horses, as has been found across a wide spectrum of mammals (e.g. [31]), and we assess the fit of our shape data to functional and developmental hypotheses for modular patterning [33] that have been previously tested in the mammalian cranium. According to Darwin's hypothesis, domesticated horses should show more variation in shape than the wild equid species. If this hypothesis is supported, then we should find differences in integration and disparity measures for cranial modules between wild equids and domesticated horses. To do so, we assess whether cranial modules display a) higher or lower magnitudes of integration and b) high or low disparity for domesticated horses and wild equids, and c) we investigate whether there is a relationship between module integration/disparity and regions of the cranium showing most variability in shape among domesticated horses.

Our aim is to characterize and quantify the patterning and magnitude of shape variation in the skulls and teeth of domesticated horses compared to the wild species of Equus. We use geometric morphometric methods to: a) test Darwin's hypothesis that the magnitude of intraspecific disparity in horses is larger than the interspecific disparity in equids, b) examine the extent to which domestication influenced tooth shape in equids, c) investigate whether the patterning of shape variation in horse skulls reflects a modular structure, specifically identifying the model best supported for the landmark data by evaluating four modular hypotheses that reflect developmental and functional trait interactions in the cranium, and d) quantify differences in the magnitude of modularity and integration between domesticated horses and wild equids.

Given the well-documented palaeontological record of horses [34], these animals offer the possibility to compare diversification in macroevolutionary and microevolutionary scale like few others. In fact, previous classic studies by Radinsky $[35,36]$ investigated some of the cranial transformations with morphometric approaches typical of that time. Our study expands the studies of the extant species using newer morphometric approaches and provides the basis for future works comparing also the fossil record of the clade.

\section{Results}

\section{Shape variation}

In the cranial symmetrised shape data, the first three principal components (PCs) account for $43.1 \%$ of the total shape variation in the cranium (Fig. 1a). PC 1 (17.6\%) tends to separate the caballine equids $(\mathrm{H}, \mathrm{P})$ from the non-caballine equids $(\mathrm{D}, \mathrm{Z})$. The shape change along PC 1 from negative to positive is dominated by a narrowing and straightening of the skull in combination with an elongation of the occipital-parietal region, represented by the cranial vault (Fig. 1b). PC 2 accounts for $15.2 \%$ of the overall observed variation, and is characterized by a general broadening of the skull in combination with an elongation of the occipital-parietal region (cranial vault module) and a shortening of the nasal region (anterior oral-nasal module). Because of the large number of landmarks compare to the relatively small number of specimens we applied a dimensionality reduction of the datasets by selecting the first PCs for all further analyses following Evin et al. [13] (mevolCVP function) that also takes into account unbalanced sample size between groups. The results of the mevolCVP function suggested the reduction of the dataset to the first three PCs in all further analyses for the cranial data. Significant differences among the four groups (Procrustes ANOVA $p<0.001, \mathrm{~F}=35.578$, based on the 6 first PCs) allowed us to perform a canonical variance analysis (CVA) with a-priori defined groups $(\mathrm{H}, \mathrm{D}, \mathrm{P}, \mathrm{Z})$ resulting in an overall classification accuracy of $78.4 \%$ (Confidence interval CI: $60 \%-95 \%$ ) when the four groups are analysed, and $98.2 \%$ (CI: 96.8\%$100 \%$, based on the 17 first PCs, Procrustes ANOVA $p<0.001, \mathrm{~F}=32.723)$ when the Przewalski horse specimens are excluded. In this later analysis, both domestic horses and donkeys could be correctly assigned to their respective groups in $100 \%$ of the cases. Zebras were assigned correctly for $95.7 \%$ of cases and the remaining $4.3 \%$ were grouped within the donkeys. Predictive discriminant analyses detect cranial shape proximities of the five Przewalski's horses with the domestic horses (100\% probabilities of identification). Domesticated and Przewalski's horses are most distinct from donkeys and zebras in Procrustes shape space, as measured by Mahalanobis distance (Table 3). Horses occupy a larger Procrustes shape space $(53.12 \%)$ as determined by Foote's partial disparity, than zebras $(26.22 \%)$ and donkeys (18.34\%). The Przewalski's horses occupy only 2 . $26 \%$ of the overall shape space. The overall Procrustes variance for the cranium is 0.0023 .

The first four PCs of the mandible shape data account for $64.1 \%$ of the total shape variation in the mandible. In contrast to the cranium, none of the PCs shows separation between any of the four groups. Specimens of all groups largely overlap in PC shape space (Fig. 1c and d), therefore we do not discuss this further. Due to 

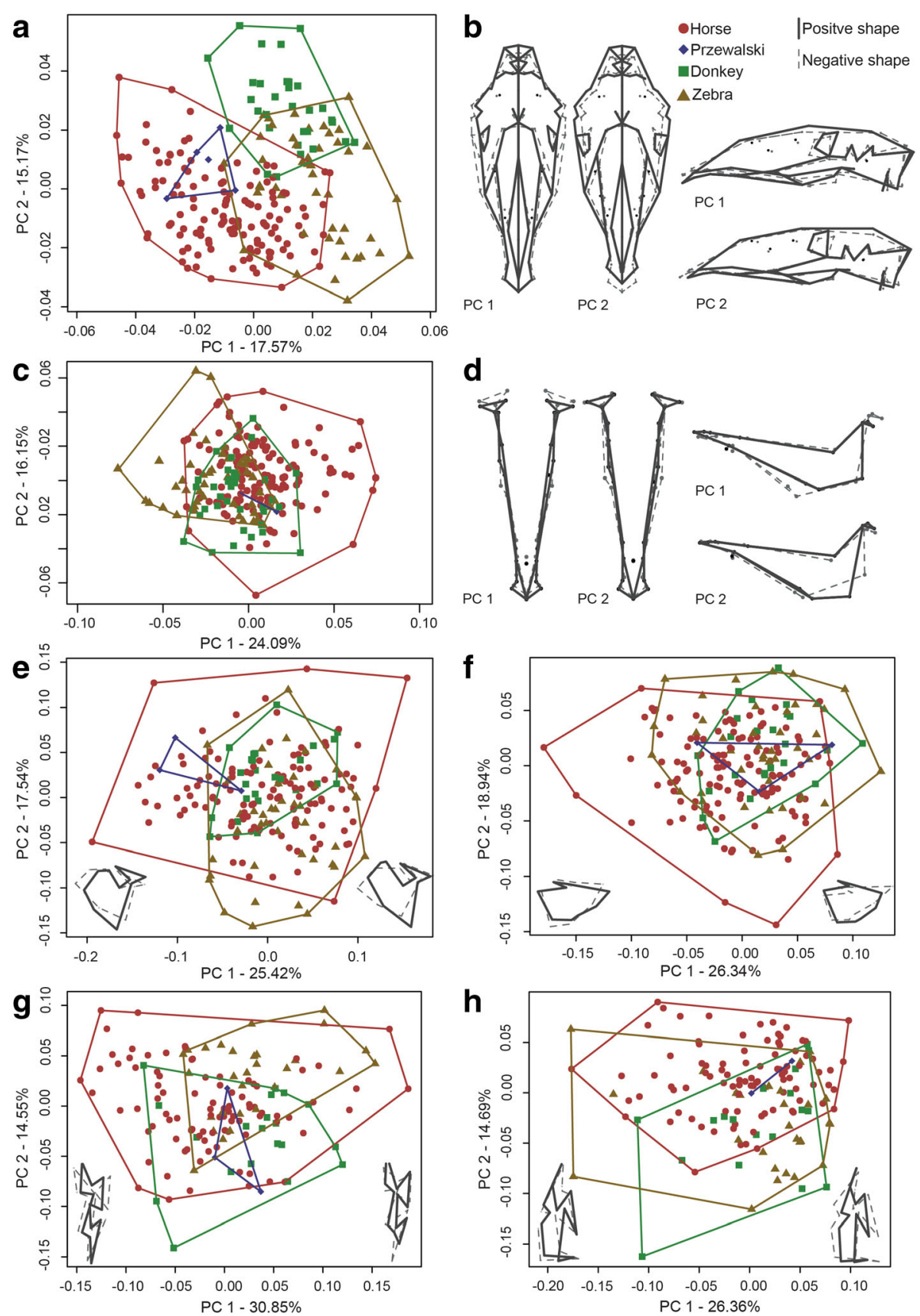

Fig. 1 Principal component analysis of a the cranial landmark data of 216 adult equid specimens: zebras $(n=47)$, donkeys $(n=31)$, Przewalski's horses $(n=5)$, and domesticated horses $(n=133)$, b Shape changes in dorsal and lateral view for PC 1 and PC 2 with black lines presenting positive shape and dotted, grey lines presenting negative shape, $\mathbf{c}$ the mandible landmark data of 224 adult equid specimens: zebras $(n=48)$, donkeys $(n=33)$, Przewalski's horses $(n=2)$, and domesticated horses $(n=141)$, $\mathbf{d}$ Shape changes in dorsal and lateral view for PC 1 and PC 2 with black lines presenting positive shape and dotted, grey lines presenting negative shape, e of the upper 3rd molar landmark data of 225 adult equid specimens: zebras $(n=42)$, donkeys $(n=25)$, Przewalski's horses $(n=3)$, and domesticated horses $(n=122)$, $\mathbf{f}$ the upper 2 rd premolar landmark data of 225 adult equid specimens: zebras $(n=42)$, donkeys $(n=25)$, Przewalski's horses $(n=3)$, and domesticated horses $(n=122)$, $\mathbf{g}$ of the lower 3 rd molar landmark data of 225 adult equid specimens: zebras $(n=29)$, donkeys $(n=20)$, Przewalski's horses $(n=3)$, and domesticated horses $(n=92)$, $\mathbf{h}$ of the lower 2 rd premolar landmark data of 225 adult equid specimens: zebras $(n=29)$, donkeys $(n=20)$, Przewalski's horses $(n=3)$, and domesticated horses $(n=92) ;$ Symbols are circles: domesticated horses, diamonds: Przewalski's, triangles: zebras, and squares: donkeys 
Table 3 MAHALANOBIS DISTANCE

\begin{tabular}{|c|c|c|c|c|c|c|}
\hline & \multicolumn{3}{|c|}{ Cranium } & \multicolumn{3}{|c|}{ Mandible } \\
\hline & D & $\mathrm{H}$ & $P$ & $\mathrm{D}$ & $\mathrm{H}$ & $P$ \\
\hline $\mathrm{H}$ & \multicolumn{3}{|l|}{5.67} & \multicolumn{3}{|c|}{10.08} \\
\hline$P$ & 5.27 & 1.04 & & 6.81 & 2.66 & \\
\hline \multirow[t]{3}{*}{ Z } & 2.32 & 6.37 & 6.31 & 5.6 & 9.55 & 7.81 \\
\hline & \multicolumn{3}{|c|}{ Cranium 3M (U3M) } & \multicolumn{3}{|c|}{ Cranium 2P (U2P) } \\
\hline & $\mathrm{D}$ & $\mathrm{H}$ & $P$ & $\mathrm{D}$ & $\mathrm{H}$ & $P$ \\
\hline $\mathrm{H}$ & 1.77 & & & 2.56 & & \\
\hline$P$ & 2.61 & 1.95 & & 2.82 & 1.61 & \\
\hline \multirow[t]{3}{*}{ Z } & 1.83 & 1.58 & 2.79 & 1.85 & 2.52 & 3.13 \\
\hline & \multicolumn{3}{|c|}{ Mandible 3M (L3M) } & \multicolumn{3}{|c|}{ Mandible 2P (L2P) } \\
\hline & D & $\mathrm{H}$ & $P$ & $\mathrm{D}$ & $\mathrm{H}$ & $P$ \\
\hline $\mathrm{H}$ & 2.23 & & & 2.16 & & \\
\hline$P$ & 2.33 & 1.84 & & 2.42 & 0.96 & \\
\hline Z & 2.79 & 2.02 & 3.37 & 1.27 & 2.32 & 2.51 \\
\hline
\end{tabular}

significant results of the Procrustes ANOVA $(p<0.001$, $\mathrm{F}=14.4,3$ first PCs), we computed a CVA with the same a-priori groups used in the cranium. The overall classification accuracy was low when the four groups were analysed (H, P, D, Z) 38.4\% (CI: 12.5\%-87.5\%), while a classification accuracy of $87 \%$ (CI: $82.4 \%-91.2 \%$, 17 first PCs, $\mathrm{F}=15.681, p<0.001)$ was reached when the two Prezwalski horses were excluded. In this later analysis, $88.2 \%$ of the donkeys, $87.9 \%$ of the horses and $89.6 \%$ of the zebras were correctly classified. The two Przewalski's specimens were both classified as horses with probabilities of $100 \%$ and $72 \%$. Donkeys, zebras, and Przewalski's horses are similarly spaced from each other (Mahalanobis distance, Table 3). Mandible Procrustes shape space occupation is very similar to the cranial shape space with horses dominating the shape space (Foote's partial disparity 58.98\%). Zebras occupy the second largest shape space with $23.69 \%$, followed by donkeys (16.59\%) and Przewalski's horses (0.71\%). The Procrustes variance of the mandible $(0.0024)$ is slightly higher than in the cranium.

In the teeth of the upper tooth row, the first four PCs of the third molar (U3M) account for $66.6 \%$, and of the second premolar (U2P) for $70.1 \%$ of the shape variation. In the lower tooth row, only the first three PCs are each above $10 \%$ and account for $55.8 \%$ in the third molar (L3M) and $51.5 \%$ in the second premolar (L2P). None of the PCs show separation of the four groups from each other for any of the teeth, with specimens of all groups largely overlapping in PC shape space (Fig. 1e-h). The four groups differ in the shape of their four teeth (U3M: $p<0.001, \mathrm{~F}=2.8609,2$ first PCs; U2P: $p<0.001, \mathrm{~F}=9$. 0841, 4 first PCs; L3M: $p<0.001, \mathrm{~F}=6.1919$, 4 first PCs;
L2P: $p<0.001, \mathrm{~F}=4.4724,7$ first PCs). We computed CVAs with the same a-priori groups (H, P, D, Z) before removing the smallest group of Przewalski horse, like for the cranium and mandible analyses. The overall classification accuracy was similar among all teeth with 41.3\% (CI: $24.6 \%-66.7 \%$, 6 PCs) for U3M, 39.4\% (CI: 16.7\%66.7\%, 2 PCs) for U2P, 35\% (CI: 8.3\%-58.3\%, 4 PCs) for L3M, and $34.5 \%$ (CI: $11.9 \%-62.5 \%, 7$ PCs) for L2P. For the later comparison excluding the Przewalski's specimens, overall classification accuracy was similar among all teeth: $63.9 \%$ (CI: 56\%-70.7\%, 11 PCs) for U3M, 76.4\% (CI: $69.4 \%-83.3 \%$, 12 PCs) for U2P, 75\% (CI: 66.6\%-81. $7 \%, 8 \mathrm{PCs}$ ) for L3M and 70.9\% (CI: 63\%-79.7\%, 9 PCs) for L2P. The Przewalski's specimens show close shape proximities with horses for L2P (two specimens identified to horses with probabilities of $100 \%$ and $96.7 \%$ ) and U2P (three specimens with probabilities between 91.7\% and $95.8 \%$ ), while for L3M two of the three specimens were closer to donkeys $(65.8 \%$ and $100 \%)$ and the latest to horse (100\%), and for U3M for which two specimens were identified as close to horses (100\% and $52.9 \%)$ and one to donkey (100\%).

All analysed teeth (L2P, U2P, L3M, and U3M) have a similar partial disparity as all other analysed features: horses showing the highest partial disparity followed by zebras, donkeys, and Przewalski's horses. However, the overall disparity (Procrustes variance) differs between the teeth, with cranial P2 showing the smallest variance (0.008) while all other teeth exhibit a total variance around 0.013. The Mahalanobis distances among the groups calculated for each tooth separately are similar for cranial and mandibular P2, and cranial and mandibular M2. Przewalski's horses and zebras are in all instances most disparate. The P2 is most similar between horses and Przewalski's horses, the cranial M3 is most similar between zebras and horses and the mandibular M3 is most similar between Przewalski's horses and horses followed by the zebra (Table 3).

\section{Modularity}

Results from EMMLi indicated that, of the models tested here, the best supported model for modularity was Goswami's mammalian module hypothesis [20] with separate within-module integration and separate between-module integration (model 2d, Additional file 1: Table S1). This model had the lowest Akaike Information Criterion (AICc) value of -969.34 and a maximum likelihood of 507.97 (Additional file 1: Table S1). Goswami's mammalian module hypothesis contains six modules, these are anterior oral-nasal $(\mathrm{AON})$, cranial base $(\mathrm{CB})$, cranial vault $(\mathrm{CV})$, orbit (ORB), molar (MR), and zygomaticpterygoid (ZP) (Fig. 2, [20]). Disparity and integration values were calculated for these six modules separately for domesticated horses $(\mathrm{H})$ and wild equids $(\mathrm{P} / \mathrm{D} / \mathrm{Z})$. 
Eigenvalue dispersion values indicated that each of the six modules showed lower magnitudes of integration in domesticated horses (average $=0.68, \quad$ median $=0.72$ ) compared to wild equids (average $=0.73$, median $=0.79$ ) . For domesticated horses, eigenvalue dispersion values were lowest for $\mathrm{AON}(0.53)$ and highest for MR (0.81) (range $=0.28)$. For wild equids, integration values were lowest for ZP (0.58) and highest for MR (0.84) (range = 0.26) (Additional file 2: Table S2). The ZP module was most similar in terms of magnitude of integration between domesticated horses and wild equids (difference of $0.03,4.7 \%$ ), whereas the $\mathrm{CB}$ module had the highest integration in wild equids compared to domesticated horses (difference of $0.07,9.5 \%$, Additional file 2: Table S2). Module disparity values were higher in domesticated horses compared to wild equids for four out of six modules; these were AON, CV, MR, and ZP (Additional file 2: Table S2). Average disparity across all six modules was the same for both domesticated horses and wild equids (0.034), with disparity ranging from 0.026 (MR) to $0.046(\mathrm{ZP})$ for domesticated horses (median $=0.031$ ) and from 0.021 (MR) to 0.041 (ORB) for wild equids $($ median $=0.035)$. The ORB module showed the largest difference in disparity between the two groups. Disparity values for the AON module were most similar for domesticated and wild forms (Additional file 2: Table S2). In both wild equids and domesticated horses there is a general trend of increasing disparity with decreasing magnitude of integration. Further, the AON and ZP modules stand out from the other cranial modules as they both show higher disparity coupled with lower integration values (Fig. 2).

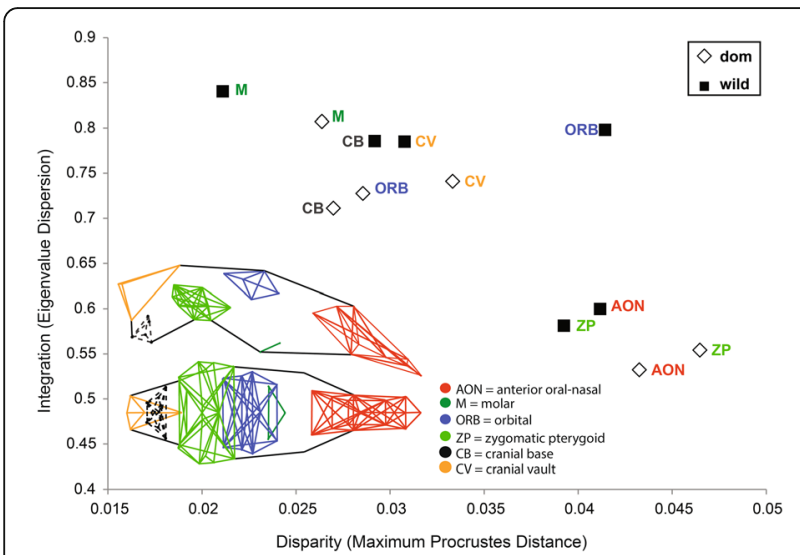

Fig. 2 a Scatterplot of calculated values for disparity ( $x$-axis) and integration (y-axis) for all modules and wild horses and domesticated equids separately; $\mathbf{b}$ Six cranial modules in a schematic horse skull (black outline) after Goswami [20] shown in lateral and dorsal perspective; Modules are: anterior oral-nasal ( $\mathrm{AON}$, red), molar (M, dark green), orbital (ORB, dark blue), zygomatic pterygoid (ZP, light green), cranial base (CB, orange), and cranial vault (CV, black dashed)

\section{Discussion}

The results of our study on skull shape variation support Darwin's hypothesis that the intraspecific disparity in horses is larger than the interspecific disparity in equids. The shape variation of domesticated horses is not only larger than that of the closest relative (Przewalski's horses) but similar to the shape variation of all the wild equid species existing today. Horses do not only dominate the Procrustes shape space when comparing crania, but also comparing mandibles or teeth - showing higher shape variation in all tested elements.

The overall classification among domesticated horses $(\mathrm{H})$, Przewalski's horses $(\mathrm{P})$, donkeys $(\mathrm{D})$, and zebras $(\mathrm{Z})$ had an average accuracy of $44.5 \%$ (range: $34.5 \%-78.4 \%$ ), which lies significantly above the random chance accuracy of $25 \%$. When we excluded the Przewalski's specimens due to their small sample size the average accuracy increased to $89.2 \%$ (range: $63.9 \%-98.2 \%$ ). The separation of caballine from non-caballine taxa and the clustering within these sister clades of $\mathrm{H} \& \mathrm{P}$, and D \& Z by the Mahalanobis distances, is in accordance with the phylogenetic relationship of equids. All four groups descend from a common ancestor around 4-4.5 myr BP, with zebras and donkeys splitting around 2.8 myr BP and Przewalski's horses and the wild ancestor of today's domesticated horses splitting 38-72 kyr BP [2, 3, 37]. The first PC of the cranial shape data tended to separate caballine from non-caballine taxa. The accompanying shape differences are dominated by an elongation of the occipital part of the cranium in zebras and donkeys, which previously have been shown to be a distinct character to separate these two taxa from the domesticated horses (for a more detailed morphological description of the skulls of each group see Table 4, Fig. 3, [38, 39]).

In contrast to the results of the cranial analysis, we did not find clear group-distinguishing shape differences in the mandible or in any of the investigated teeth. We found the highest Procrustes variance in the mandible data set, very closely followed by the cranium. All four teeth showed a lower Procrustes variance pointing towards less variability, a result also reflected in the low magnitude of disparity for landmarks belonging to the molar (MR) module, probably related to dietary constraints. Our findings on tooth shape differences are congruent with the "long-fuse" hypothesis on teeth by Seetah et al. [14], stating that "shape changes in equids have been modest [...] until the development of modern breeds in recent centuries". Cucchi et al. [16], however, found a strong taxonomic pattern in the shape of the enamel folding, allowing for a more distinct taxonomic separation at the species level. These resulting differences are most likely due to the different choice of teeth ([14]: UP4; [16]: LP3 - LM2) , as suggested by one of the articles [16], different 


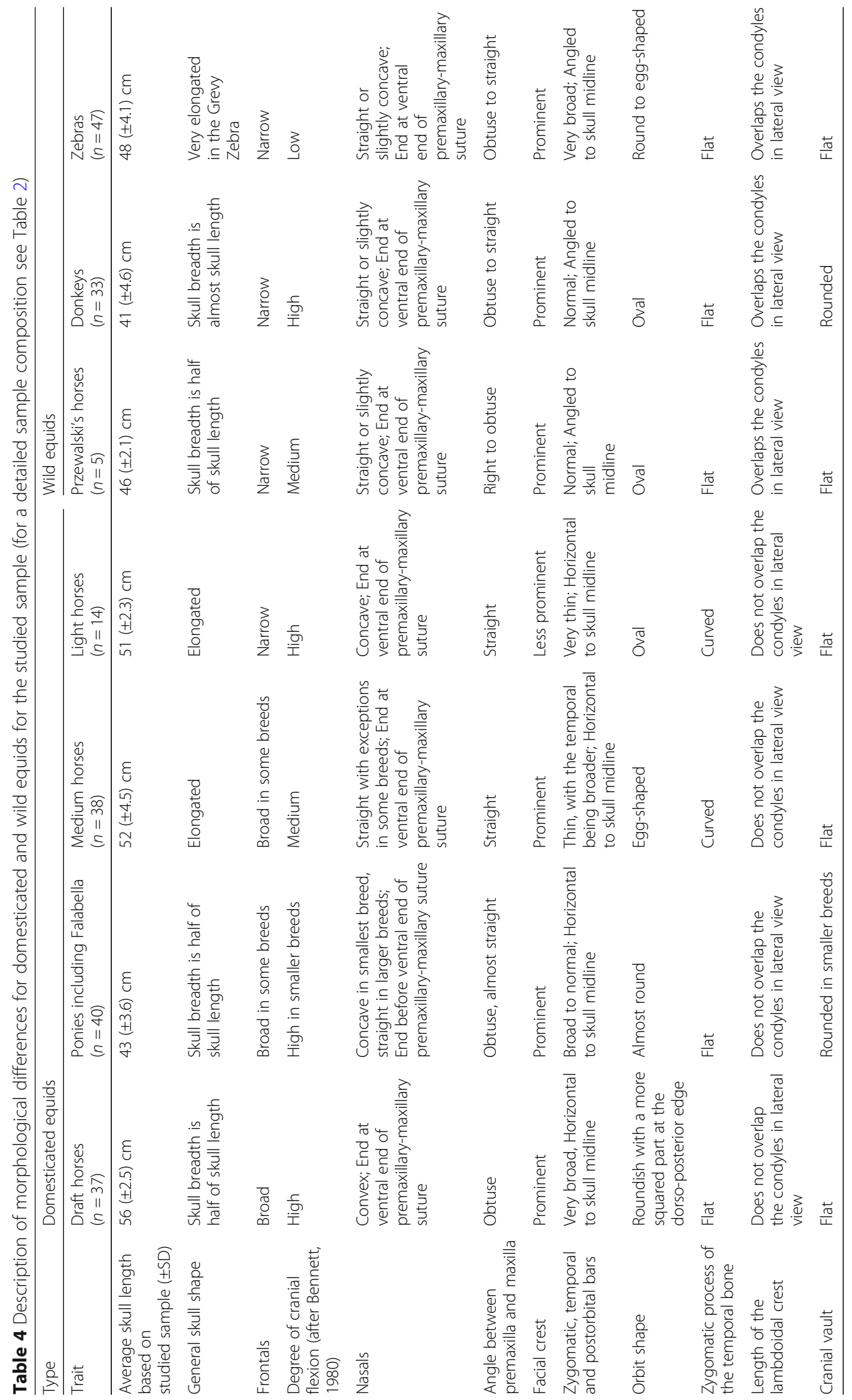



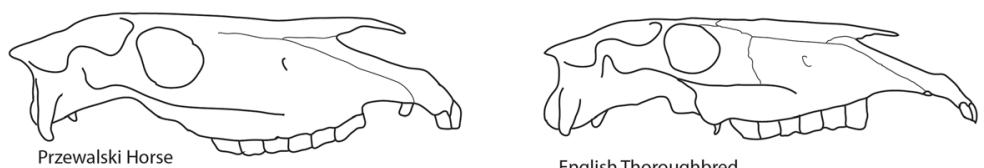

English Thoroughbred
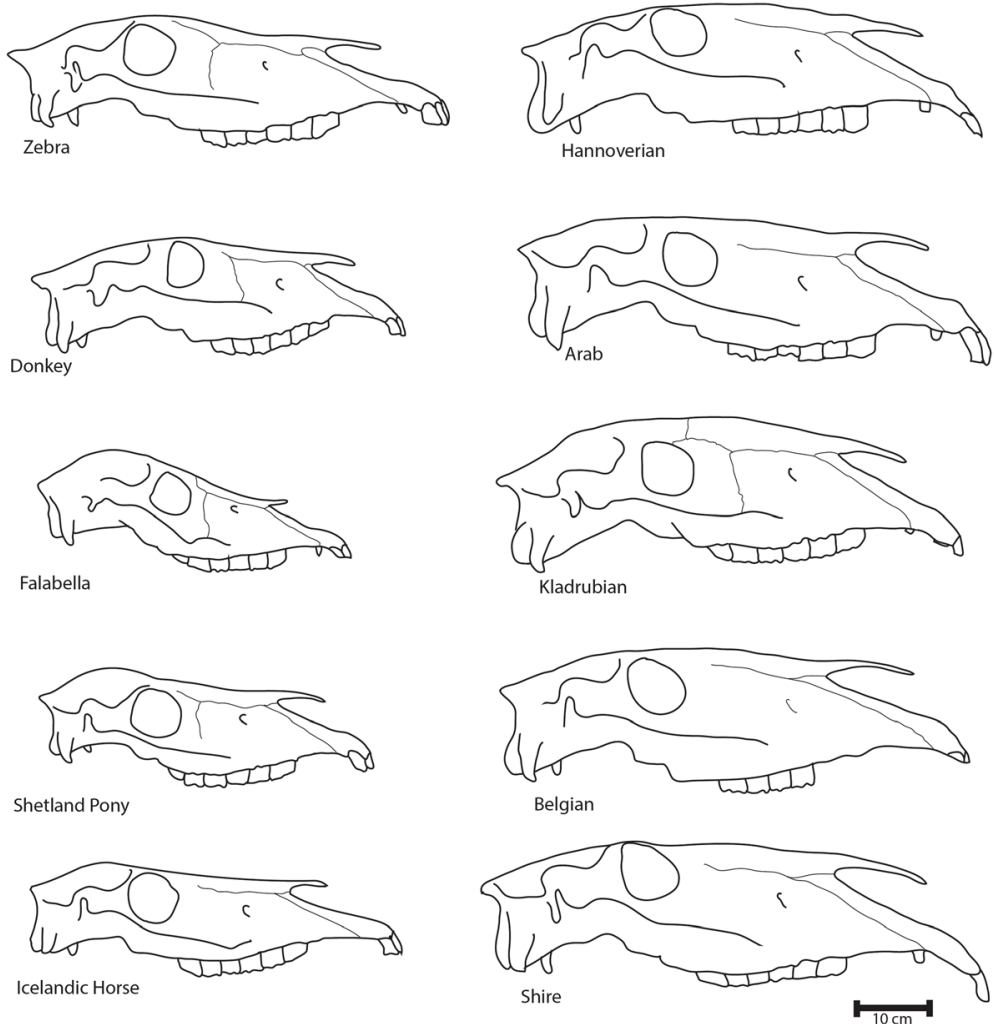

Fig. 3 Examples for skull shapes from lateral view of different domesticated (Draft: Shire, Belgian; Light horse: Arab; Medium horses: Hannoverian, Kladrubian, Engl. Thoroughbred; Ponies: Falabella, Shetland, Icelandic) and wild equids (Przewalski's horse, Zebra, Donkey)

wear stages, and/or the different methods used (landmarks vs. semilandmarks).

Modular patterning of the cranium is well-supported by empirical evidence, representing shared development and functional associations between parts of the cranium, resulting in their parcellation into semi-autonomous units. Consistent with patterns recovered for other placental mammals [20], our results indicate that trait variation in the equid cranium is best supported by a six-module hypothesis. These six modules reflect functional groups: the anterior oral-nasal (AON) and molar (MR) modules represents the primary masticatory apparatus, the zygomaticpterygoid (ZP) module includes the region of attachment for masticatory muscles, the orbit (ORB) module contains the visual sensory organs, the cranial vault $(\mathrm{CV})$ supports and protects the brain, and the cranial base (CB) supports the braincase and is the point of attachment between the skull and axial skeleton. Previous analyses of module disparity and integration for these six modules in a sample of carnivorans provided some support for highly integrated modules showing low disparity, particularly the basicranium $(\mathrm{CB})$, and weakly integrated modules showing high disparity (ORB and ZP) [20, 28]. Our results are broadly consistent with this trend (Fig. 2), which is suggestive of strong integration acting to limit trait variation or the direction of response to selection. The ZP module in horses is also found to be weakly integrated and showing high disparity. Among the carnivoran sample, the molar region showed an unusual pattern of high disparity and high levels of integration [28], in our sample the molar module is also recovered as the most highly integrated module but displays the lowest levels of disparity for both wild and domesticated forms. The discrepancy between these results is likely explained by the diversity of dietary habits represented by the carnivoran sample (e.g. hypercarnivores, insectivores, frugivores) in that earlier study, which resulted in a high disparity among the landmarks captured in the molar module. 
Selection acting on shared developmental and functional processes can result in an uncoupling of trait associations at different levels [40-43], providing evidence for complex interactions between modularity and selection. Following, it might therefore be expected that domestication events, as examples of selective breeding regimes, could alter patterns of modularity and integration, and these alterations may differ among breeds, acknowledging that the features targeted for selection (e.g. gait, conformation) are likely to differ for some breeds. There exist few empirical tests of this hypothesis and results on dogs are inconclusive, with reports that patterns of integration have remained stable despite the morphological diversification associated with domestication [9, 44 ], but also that high module disparity is associated with greater cranial shape variation in dogs compared to wolves [45]. In contrast to Parr et al. [45] our results show highly similar magnitudes of module disparity among wild and domesticated forms, and instead lower magnitudes of module integration are recovered in domesticated horses compared to their wild relatives. Variability in integration magnitude, as recovered here, rather than patterning has been proposed to underlie cranial diversity in mammals [31,32], such that general conservatism in patterning across mammals may be explained as a product of stabilizing selection on basic developmental processes whereas directional selection could act by altering magnitudes of integration. A recent study conducted simulations to test the role of integration in generating morphological disparity and noted that integration may not affect disparity in morphospace in the way that it is usually measured (as a volume of occupied morphospace or as a measure of dissimilarity), making the relationship between morphospace occupation and modularity results potentially difficult to interpret [46]. That study did not compare shape variation and its partitioning into modules, however our PCA plots indicate that the main axes of shape variation in the equid sample are spread across landmarks located in at least three modules (CV, AON and ZP). Similarly, Parr et al. [45] found shape variance in wild and domesticated dogs to be spread across modules with different magnitudes of integration. It has been suggested that modularity may repartition variance along new directions in morphospace, thereby exploring a greater volume, however the so-far limited empirical evidence appears to raise the question of the extent to which those new directions may be aligned with the axes recovered by eigen-decomposition of shape variables into mathematically orthogonal axes, as happens in ordination techniques such as PCA.

\section{Methods}

A total of 216 crania, 224 mandibles, 198 upper and 141 lower second premolars (U2P and L2P respectively), and
192 upper and 144 lower third molars (U3M and L3M respectively) were analysed (Table 2).

We examined specimens from the following collections: Museum für Naturkunde Berlin (MfN Berlin, Germany), Institut für Haustierkunde (Christian-Albrechts-Universität of Kiel, Germany), Museum für Haustierkunde "Julius Kühn" (University of Halle, Germany), Naturhistorisches Museum Wien (NHW Vienna, Austria), and Museo de la Plata (MLP La Plata, Argentina). The dataset includes all recent species of the genus Equus [37]. Due to inconsistent species assignment within zebras and donkeys across museums, we analysed all zebra (cranium $n=47$; mandible $n=48$ ) and donkey (cranium $n=31$; mandible $n=33$ ) species as one group, respectively. We further included five crania and two mandibles of Przewalski's horses. The largest number of specimens in our data set belongs to the domesticated horses (cranium $n=133$; mandible $n=141$ ) including the following breeds: Ancient Breed (Roman period), Anglo-Norman, Arab, Birkenfelder, Belgian Draft, Bosnian Pony, Clydesdale, Exmoor Pony, Falabella, Galician Farm Horse, Grisons (Graubündner), German Riding Pony, Hannoverian, Hackney, Holstein, Hungarian, Huzule, Icelandic Horse, Indian Pony, Kladrubian, Konik, Kosarian, Lipizzan, Mongolian, Norik, Oldenburgian, Pinzgau, Polish Farm Horse, Scottish Pony, Seneca Sarajevo, Shetland Pony, Shire, Styrian, Suffolk, English Thoroughbred, Togo Pony, Trakehner, and Welsh (Table 2).

Analyses of cranial, mandibular and teeth size and shape were performed using landmark-based geometric morphometric (GMM) approaches. The crania and mandibles were measured in three-dimension (3D) using a MicroScribe ${ }^{\circ}$ MLX6 (Revware, Inc., Raleigh, North Carolina, USA), while the teeth were measured in two-dimension (2D) using high resolution photographs. A total of 62 type I and type II landmarks [47] were collected on the cranium (Table 5, Additional file 3). The dorsal and ventral sides of the crania (Fig. 4) were measured separately and were subsequently combined using three reference landmarks (numbered 1, 2, and 33, Table 5). For the mandible 24 type II landmark coordinates were measured (Table 5, Fig. 4, Additional file 3).

Phenotypic variation of the four studied teeth was assessed using 9 to 12 two-dimensional landmarks (Type II) (Table 5, Fig. 4, Additional file 4, 5, 6 and 7) following Seetah et al. [48] for the upper teeth that was adapted for the lower teeth. The landmark coordinates were collected on high resolution photographs using TPSDig2 [49]. The photographs were all taken in a standardized manner using a Canon Eos 600d with a Canon EF 24-105 mm f/4 L S USM lens from lateral and dorsal view with a scale bar for size reference.

\section{Geometric morphometric analyses}

To eliminate the effects of size, orientation, and scaling we performed General Procrustes Analysis (GPA, [50]), 
Table 5 Description of the landmarks, including position and type, collected on each cranium, mandible, and tooth; Type I: discrete juxtapositions of tissue types and Type II: maxima of curvature or other local morphogenetic processes [37]

\begin{tabular}{|c|c|c|}
\hline & Position & Type \\
\hline \multicolumn{3}{|l|}{ Cranium } \\
\hline $1-2$ & Posterior tip of the upper third incisor & $\|$ \\
\hline $3-4$ & Posterior most point of the nasal-premaxilla suture & I \\
\hline $5-6$ & Premaxillary-maxillary-nasal suture & । \\
\hline $7-8$ & Dorsoposterior tip of the infraorbital foramen & $\|$ \\
\hline $9-10$ & Anterior tip of the facial crest & $\|$ \\
\hline 11 & Nasion, nasal-frontal suture, midline & 1 \\
\hline $12-13$ & Junction of the lacrimal, maxilla, and nasal sutures & I \\
\hline $14-15$ & Zygo-lacrimal suture on the orbital margin & । \\
\hline $16-17$ & Lacrimal-frontal suture on the orbital margin & । \\
\hline $18-19$ & Supraorbital foramen & $\|$ \\
\hline $20-21$ & Anterior tip of the zygo-temporal suture & I \\
\hline $22-23$ & Posterior tip of the zygo-temporal suture & I \\
\hline $24-25$ & Dorsal tip of the frontal-temporal suture & I \\
\hline $26-27$ & Ventroposterior tip of the zygomatic process & $\|$ \\
\hline $28-29$ & $\begin{array}{l}\text { Dorsalmost point of the vertically orientated posterior margin of } \\
\text { the zygomatic process }\end{array}$ & $\|$ \\
\hline $30-31$ & Ventrolateralmost point of squamous part of temporal bone & $\|$ \\
\hline 32 & Anterior tip of the occipital triangle & । \\
\hline 33 & Posterior tip of the nuchal crest & $\|$ \\
\hline $34-35$ & Dorsolateral tip of the nuchal crest & $\|$ \\
\hline 36 & Dorsalmost point on the margin of the foramen magnum & $\|$ \\
\hline 37 & Point between first incisors from ventral side & $\|$ \\
\hline $38-39$ & Posteriormost tip of the premaxillary-maxillary suture, ventral & । \\
\hline $40-42$ & Anterior tip of the second premolar & $\|$ \\
\hline $41-43$ & Posterior tip of the third molar & $\|$ \\
\hline 44 & Posteriormost point of the incisive canal & $\|$ \\
\hline 45 & Posterior tip of the palatine process of the incisive bone & 1 \\
\hline 46 & Posterior tip of the palatine-palatine suture & I \\
\hline $47-48$ & Distal tip of the pterygoid hamulus & $\|$ \\
\hline $49-51$ & Anterior tip of the caudal alar foramen & $\|$ \\
\hline 50 & Posterior tip of the vomer on the midline & $\|$ \\
\hline $52-53$ & Medial tip of the mandibular fossa & $\|$ \\
\hline $54-55$ & Canal for hypoglossal nerve & $\|$ \\
\hline $56-57$ & Fossa medial of the paracondylar process & $\|$ \\
\hline $58-59$ & Distal tip of the paracondylar process & $\|$ \\
\hline 60 & Ventral tip of the foramen magnum & $\|$ \\
\hline $61-62$ & Posteriormost tip of the occipital condyle & $\|$ \\
\hline \multicolumn{3}{|l|}{ Mandible } \\
\hline U1 & Posterior point between first incisors & $\|$ \\
\hline U2-U3 & Posterior tip of the third lower incisor & $\|$ \\
\hline U4-U5 & Posterior tip of the canine & $\|$ \\
\hline U6 & Posterior tip of the mandible on the midline & $\|$ \\
\hline U7-U8 & Anterior tip of the second premolar & $\|$ \\
\hline
\end{tabular}


Table 5 Description of the landmarks, including position and type, collected on each cranium, mandible, and tooth; Type I: discrete juxtapositions of tissue types and Type II: maxima of curvature or other local morphogenetic processes [37] (Continued)

\begin{tabular}{|c|c|c|}
\hline & Position & Type \\
\hline U9-U10 & Posterior tip of the third molar & $\|$ \\
\hline U11-U12 & Junction of the bases of the coronoid and condylar processes & $\|$ \\
\hline U13-U14 & Lateral tip of the condylar process & $\|$ \\
\hline U15-U16 & Medial tip of the condylar process & $\|$ \\
\hline U17-U18 & Posterior tip of the mandibular mental foramen & $\|$ \\
\hline U19-U20 & Vascular notch of the mandible & $\|$ \\
\hline U21-U22 & $\begin{array}{l}\text { Maximum curvature of the angle of the mandible right } \\
\text { behind the vascular notch }\end{array}$ & $\|$ \\
\hline U23-U24 & Maximum curvature of the angle of the mandible & $\|$ \\
\hline \multicolumn{3}{|l|}{ Cranium 2P } \\
\hline 1 & Maximum curvature of the metastyle & $\|$ \\
\hline 2 & Maximum curvature of the mesostyle, distal side & $\|$ \\
\hline 3 & Maximum curvature of the mesostyle, medial side & $\|$ \\
\hline 4 & Maximum curvature of the anterior accessory rib & $\|$ \\
\hline 5 & Maximum curvature of the parastyle & $\|$ \\
\hline 6 & Maximum curvature of the protocone, mesial/labial side & $\|$ \\
\hline 7 & Maximum curvature of the protocone, buccal side & $\|$ \\
\hline 8 & Maximum curvature of the protocone, distal/labial side & $\|$ \\
\hline 9 & Maximum curvature of the hypocone & $\|$ \\
\hline \multicolumn{3}{|l|}{ Cranium $3 \mathrm{M}$} \\
\hline 1 & Maximum curvature of the metastyle & $\|$ \\
\hline 2 & Maximum curvature of the mesostyle & $\|$ \\
\hline 3 & Maximum curvature of the parastyle & $\|$ \\
\hline 4 & Maximum curvature of the preprotoconal groove & $\|$ \\
\hline 5 & Maximum curvature of the protocone, mesial side & $\|$ \\
\hline 6 & Maximum curvature of the protocone, distal side & $\|$ \\
\hline 7 & Maximum curvature of the post protoconal valley, buccal side & $\|$ \\
\hline 8 & Maximum curvature of the post protoconal valley, labial side & $\|$ \\
\hline 9 & Maximum curvature of the hypocone, buccal side & $\|$ \\
\hline 10 & Maximum curvature of the hypocone, labial side & $\|$ \\
\hline \multicolumn{3}{|l|}{ Mandible 2P } \\
\hline 1 & Maximum curvature of the protoconid, anterior/ lingual side & $\|$ \\
\hline 2 & Maximum curvature of the preflexid, anterior side & $\|$ \\
\hline 3 & Maximum curvature of the preflexid, posterior side & $\|$ \\
\hline 4 & Maximum curvature of the metaconid, anterior side & $\|$ \\
\hline 5 & Maximum curvature of the metastylid, posterior side & $\|$ \\
\hline 6 & Maximum curvature of the postflexid, anterior side & $\|$ \\
\hline 7 & Maximum curvature of the postflexid, posterior side & $\|$ \\
\hline 8 & Maximum curvature of the hypoconulid, posterior side & $\|$ \\
\hline 9 & Maximum curvature of the hypoconid, anterior/ buccal side & $\|$ \\
\hline 10 & Maximum curvature of the ectoflexid, lingual side & $\|$ \\
\hline 11 & Maximum curvature of the protoconid, posterior/ buccal side & $\|$ \\
\hline 12 & Maximum curvature of the protoconid, anterior/ buccal side & $\|$ \\
\hline
\end{tabular}


Table 5 Description of the landmarks, including position and type, collected on each cranium, mandible, and tooth; Type I: discrete juxtapositions of tissue types and Type II: maxima of curvature or other local morphogenetic processes [37] (Continued)

\begin{tabular}{|c|c|c|}
\hline & Position & Type \\
\hline \multicolumn{3}{|c|}{ Mandible $3 \mathrm{M}$} \\
\hline 1 & Maximum curvature of the hypoconulid, posterior side & $\|$ \\
\hline 2 & Maximum curvature of the entoconid, anterior side & $\|$ \\
\hline 3 & Maximum curvature of the entoflexid, posterior side & $\|$ \\
\hline 4 & Maximum curvature of the entoflexid, anterior side & $\|$ \\
\hline 5 & Maximum curvature of the metastylid, posterior side & $\|$ \\
\hline 6 & Maximum curvature of the metaconid, anterior side & $\|$ \\
\hline 7 & Maximum curvature of the metaflexid, posterior side & $\|$ \\
\hline 8 & Maximum curvature of the protoconid, anterior side & $\|$ \\
\hline 9 & Maximum curvature of the protoconid, posterior side & $\|$ \\
\hline 10 & Maximum curvature of the ectoflexid, lingual side & $\|$ \\
\hline 11 & Maximum curvature of the hypoconid, anterior/ buccal side & $\|$ \\
\hline 12 & $\begin{array}{l}\text { Maximum curvature between the hypoconid and } \\
\text { hypoconulid, lingual side }\end{array}$ & $\|$ \\
\hline
\end{tabular}

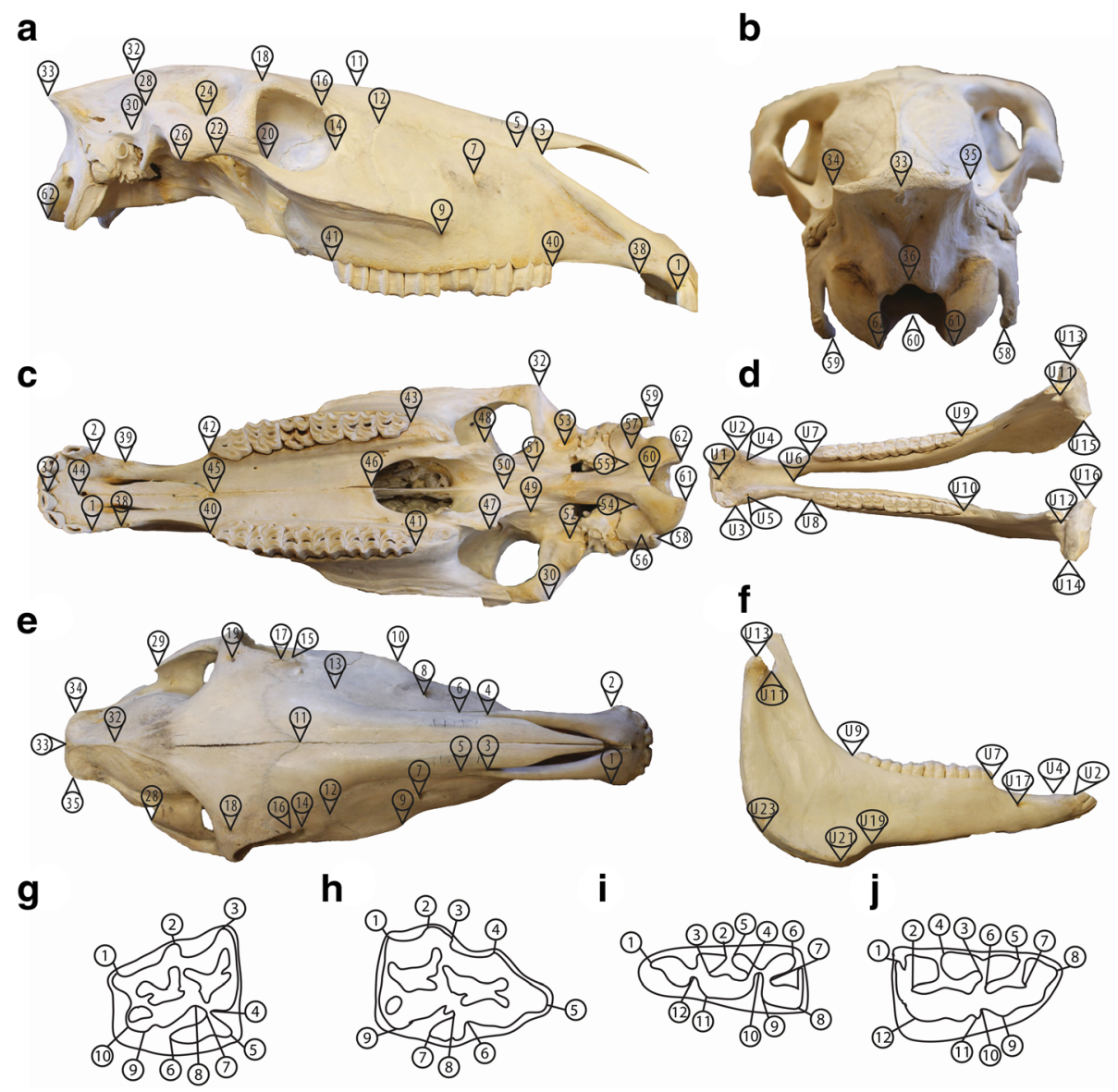

Fig. $\mathbf{4}$ Landmarks on the $\mathbf{a}$ lateral $\mathbf{b}$ ventral $\mathbf{c}$ dorsal $\mathbf{d}$ posterior side of the skull and the $\mathbf{e}$ dorsal $\mathbf{f}$ lateral side of the mandible of a domesticated horse (for a detailed description of the landmarks see Table 3); Landmarks on the $\mathbf{g}$ upper 3rd molar $\mathbf{h}$ upper 2nd premolar $\mathbf{i}$ lower 3rd molar j lower 2nd premolar of a zebra (specimen MfN 70,299) in occlusal view (for a detailed description of the landmarks see Table 3) 
which translates all specimens' coordinates so their centroid coincides, scales them to unit centroid size, and rotates them to minimize squared summed distances between matching landmarks. With the cranium and the mandible being symmetric objects, only the symmetric component of shape was analysed in subsequent procedures [51]. The Procrustes scores retained from the GPAs for each skeletal feature were subjected to Principal Component Analyses (PCA). Differences in shape among the four different equid taxa were explored using Procrustes analysis of variance (ANOVA) [52] with shape ( $\mathrm{PC}$ scores) as the dependent and group (horses $[H]$, Przewalski's horses $[P]$, zebras $[\mathrm{Z}]$, and donkeys $[D]$ ) as the independent variable. Canonical Variance Analyses (CVA) was then performed to identify the shape features which best characterize the different groups. Due to the high dimensionality of the datasets, a dimensionality reduction was performed prior to the ANOVA and CVA analyses using the mevolCVP function in $\mathrm{R}$ [12]. The mevolCVP function helps to identify the appropriate number of dimensions (first PC scores) which maximize the cross-validated percentage in the subsequent analyses using leave-one-out cross-validated linear discriminant analyses (LDA) (for a more detailed explanation see [53]). We then only used the predetermined number $(\mathrm{N})$ of first PC scores to test for differences in shape among the defined groups using Procrustes ANOVA. If the Procrustes ANOVA showed significant results, we performed a Canonical Variance Analysis (CVA) to identify the shape features which best characterize the different groups. Because sample sizes of Przewalski's horses were relatively small, CVA analyses were performed with and without them. When they were excluded, predictive CVAs were used to assess the proximity of these specimens with the three remaining groups (identification were based on resampled designs [15]).

We determined distances among the groups by calculating squared Mahalanobis distances $\left(D^{2}\right)$, which represents the distance of one group mean to another group mean in standard deviations.

Further, we analysed the morphological disparity (as Procrustes variance, [52]) which is the occupied space of all specimens together in multidimensional shape space [54]. First, we calculated the grand mean in unit Procrustes variances. Then we inferred and compared Foote's partial disparity (PD) $[54,55]$ to the grand mean. PD was calculated for each group (H, P, D, Z) separately, and for wild equids (D, Z, P) and domesticated horses $(\mathrm{H})$. To do so, the residuals from the regression of shape across all specimens were used and the squared residual lengths were summed over either group mean. The resulting group wise Procrustes variances were multiplied by the number of samples per group divided by total sample size minus one. We then calculated the contribution in percent of each group to the overall disparity.

Analyses were conducted using R [56] in RStudio (v.1. 0.136 ) and related $R$ packages $[52,57,58]$ ( $R$ script is available upon request). The analyses were computed separately for the cranium, the mandible, and each of the four teeth.

\section{Modularity analyses}

Cranial landmarks for the total sample (wild equids and domesticated horses) were tested for modular structure using 17 models. Wild equids and domesticated horses were pooled because modular patterning has been demonstrated to be stable across placental mammals [20,31, 32]. With the exception of the simplest model (= no modularity), cranial landmarks were subdivided into modules following a priori hypotheses for modular patterning. These were: 1 ) Tissue origin hypothesis (neural crest vs paraxial mesoderm derived elements [33]), 2) adult module hypothesis [20], 3) Cheverud's functional module hypothesis [59], and 4) horse-specific hypothesis [35, 60] (see Additional file 8: Table S3). Hypotheses \#1-3 have previously been tested on a macroevolutionary scale in mammals whereas hypothesis \#4 tests the face and neurocranium as two separate units based on previously recovered growth pattern differences of the face relative to the neurocranium in horse evolution $[35,36,60]$. For each of these competing hypotheses (\#1-4) we compared the fit of our data to different model structures, allowing for variation in correlation within and between modules. As such, each hypothesis was evaluated for four variants (a-d), these were a) same withinmodule integration and same between-module integration, b) same within-module integration and separate between-module integration, c) separate within-module integration and same between-module integration, and d) separate within-module integration and separate between-module integration (see Additional file 8: Table S3). The fit of the 17 models (4 hypotheses $\times 4$ variants [a-d, above] plus 'no modularity' hypothesis) was evaluated using the EMMLi package version 0.0.3 [22] in R, using a coordinate (Procrustes aligned) correlation matrix based on absolute values of correlations as input. EMMLi is a maximum likelihood approach that allows for the direct comparison of models of mixed complexity, and outputs a corrected Akaike Information Criterion (AICc) value and an AICc difference (dAICc), which can be used to assess the fit of the model to the data [22].

The best supported model of modularity (lowest AICc and smallest $\mathrm{dAICc}$ ) recovered from the EMMLi analysis was chosen for further calculations of module disparity and integration and comparisons between wild and domesticated forms. The cranial landmark matrix was 
subdivided into matrices for domesticated horses and wild equids. The matrices for domesticated horses and wild equids were each further subdivided into modulespecific landmark sets (e.g. orbit module domesticated horses, orbit module wild equids) and subject to GPA. For each module, disparity of the landmarks within that module was defined as maximum Procrustes distance following previous studies (e.g. [45]), and was calculated using Procrustes distances between the mean shape landmark configuration and the landmark configuration of each specimen. Disparity calculations were performed using the Evomorph package version 0.9 [61] in R. For each module, integration of the landmarks within that module was calculated using relative eigenvalue standard deviation (i.e. eigenvalue dispersion), following calculations detailed in [62]. This measure assesses the variance of extracted eigenvalues, which would be maximal when all variation in the data is found in a single dimension (i.e. complete integration) and zero when all eigenvalues are equal (i.e. no integration [30]). Therefore, large values for eigenvalue dispersion reflect strong integration between the landmarks in a module. Eigenvalue dispersion has been shown to be independent of trait number and highly correlated with the mean squared correlation coefficient [32].

\section{Conclusion}

We described and compared shape changes in various skeletal features among extant equid species using geometric morphometrics. Our results support Darwin`s hypothesis that shape variation in the skull of domesticated horses is similar to the shape variation of all wild extant equid species. Our study further shows that lower magnitudes of integration among six cranial modules are found in domesticated horses compared to their wild relatives. Future research could address the relation between integration and disparity, investigating the relation between the two during the domestication process of diverse species.

\section{Additional files}

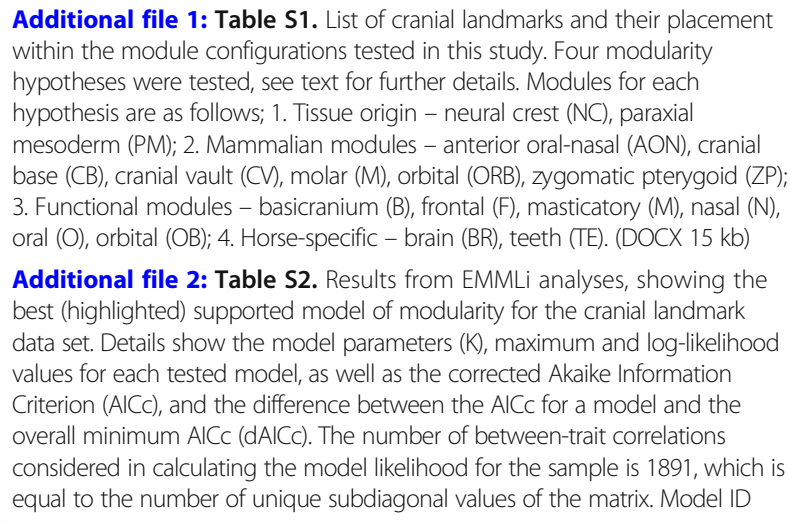

values correspond to those provided in the Material and Methods text. (DOCX 15 kb)

Additional file 3: Raw data for crania and mandibles for all specimens used in this study including three-dimensional landmark data (raw coordinates) and identifier; ID_String is the individual combination including all information: Museum ( $\mathrm{A}=$ Argentina, $\mathrm{B}=$ Berlin, $\mathrm{H}=$ Halle, $\mathrm{K}=$ Kiel, $\mathrm{V}=$ Vienna), ID (identifier used at the museum), group $(H=$ horse, $D=$ donkey, $P=$ Przewalski's, $Z=$ zebra), breed (aaa = not a domesticated horse, ahb = Ancient Breed (Roman period), ano = Anglo-Norman, $\mathrm{arb}=$ Arab, bif $=$ Birkenfelder, $\mathrm{blg}=$ Belgian Draft, bos = Bosnian Pony, cds = Clydesdale, exm = Exmoor Pony, fab = Falabella, gbh = Galician Farm Horse, grb = Grisons (Graubündner), grp = German Riding Pony, han = Hannoverian, hny = Hackney, hol = Holstein, hun = Hungarian, huz $=$ Huzule, ice $=$ Icelandic Horse, ind = Indian Pony, $k d r=$ Kladrubian, kon = Konik, kos = Kosarian, Ipz = Lipizzan, mon = Mongolian, nor = Norik, odb $=$ Oldenburgian, piz $=$ Pinzgau, pll = Polish Farm Horse, $\mathrm{scp}=$ Scottish Pony, ses $=$ Seneca Sarajevo, she $=$ Shetland Pony, shi $=$ Shire, stm = Styrian, suf $=$ Suffolk, tbh = English Thoroughbred, tog = Togo Pony, trk = Trakehner, and wel $=$ Welsh), and morphotype ( $\mathrm{A}=$ not a domesticated horse, $\mathrm{W}=$ medium horse, $\mathrm{F}=$ Light horse, $\mathrm{C}=$ Draft horse, $\mathrm{P}=$ Pony). (XLSX $13 \mathrm{~kb}$ )

Additional file 4: TpsDig output for 2) upper third molar, 3) upper second premolar, 4) lower third molar, and 5) lower second premolar for all specimens used in this study including two-dimensional landmark data (raw coordinates) and identifier (image name); for details see Additional file 1. (TXT $13 \mathrm{~kb}$ )

Additional file 5: TpsDig output for 2) upper third molar, 3) upper second premolar, 4) lower third molar, and 5) lower second premolar for all specimens used in this study including two-dimensional landmark data (raw coordinates) and identifier (image name); for details see Additional file 1. (TXT $12 \mathrm{~kb}$ )

Additional file 6: TpsDig output for 2) upper third molar, 3) upper second premolar, 4) lower third molar, and 5) lower second premolar for all specimens used in this study including two-dimensional landmark data (raw coordinates) and identifier (image name); for details see Additional file 1. (TXT $12 \mathrm{~kb}$ )

Additional file 7: TpsDig output for 2) upper third molar, 3) upper second premolar, 4) lower third molar, and 5) lower second premolar for all specimens used in this study including two-dimensional landmark data (raw coordinates) and identifier (image name); for details see Additional file 1. (TXT $12 \mathrm{~kb}$ )

Additional file 8: Table S3. Module disparity and integration values calculated separately for domesticated and wild horses. Modules are, anterior oral-nasal (AON), cranial base (CB), cranial vault (CV), molar (MR), orbital (ORB), and zygomatic-pterygoid (ZP), as recovered by Goswami (2006) (see Materials and Methods for further details). (DOCX 14 kb)

\section{Acknowledgements}

We thank the many institutions and people giving us access to their collections: Christiane Funk and Frieder Mayer (MfN Berlin, Germany), Renate Lücht (Institut für Haustierkunde, Christian-Albrechts-Universität of Kiel, Germany), Renate Schafberg (Museum für Haustierkunde "Julius Kühn", University of Halle, Germany), Frank Zachos, Alexander Bibl, Konstantina Saliari and Erich Pucher (NHW Vienna, Austria), and Alfredo Carlini (MLP La Plata, Argentina). We thank Borja Esteve-Altava and an anonymous reviewer for thorough and useful comments that helped us improved the manuscript and John A. Nyakatura for editorial work.

\section{Funding}

This work was supported by SNF grant 31003A_169395 to MRS-V. Support for the collection visit at the NHW Vienna, Austria was granted by SYNTHESYS funding AT-TAF-5786 "Morphological disparity and ontogenetic allometry in domesticated horses" to LH. LABW is supported by the Discovery Program of the Australian Research Council (DE150100862).

\section{Availability of data and materials}

The datasets used and/or analysed during the current study are available in the supplementary information to this article. 


\section{Authors' contributions}

LH collected the data and performed and interpreted the geometric morphometric analyses. LABW performed and interpreted the modularity analyses. AE provided the R functions and pipeline used in the geometric morphometric analyses. MS performed and interpreted the Foote's partial disparity analyses and supported LH during the geometric morphometric analyses. MRS-V conceived and supervised the entire study. All authors read and approved the final manuscript.

\section{Ethics approval and consent to participate}

Not applicable.

\section{Consent for publication}

Not applicable

\section{Competing interests}

The authors declare that they have no competing interests.

\section{Publisher's Note}

Springer Nature remains neutral with regard to jurisdictional claims in published maps and institutional affiliations.

\section{Author details}

'Palaeontological Institute and Museum, University of Zurich, 8006 Zurich, Switzerland. ${ }^{2}$ Palaeontology, Geobiology and Earth Archives Research Centre, School of Biological, Earth and Environmental Sciences, University of New South Wales, Sydney, NSW 2052, Australia. Institut des Sciences de I'Evolution - Montpellier, CNRS UMR 5554, Université de Montpellier, IRD, EPHE, 2 place Eugène Bataillon, 34095 Montpellier, France. ${ }^{4}$ Department of Archaeology, Classics and Egyptology, University of Liverpool, Liverpool, UK

\section{Received: 27 October 2017 Accepted: 19 March 2018}

\section{Published online: 19 April 2018}

\section{References}

1. Francis RC. Domesticated: evolution in a man-made world. New York: WW Norton \& Company; 2015.

2. Orlando L, Metcalf JL, Alberdi MT, Telles-Antunes M, Bonjean D, Otte M, Martin F, Eisenmann V, Mashkour M, Morello F. Revising the recent evolutionary history of equids using ancient DNA. Proc Natl Acad Sci. 2009; 106(51):21754-9.

3. Schubert M, Jónsson H, Chang D, Der Sarkissian C, Ermini L, Ginolhac A, Albrechtsen A, Dupanloup I, Foucal A, Petersen B. Prehistoric genomes reveal the genetic foundation and cost of horse domestication. Proc Natl Acad Sci. 2014;111(52):E5661-9.

4. Orlando L. Equids. Curr Biol. 2015:25(20):R973-8.

5. Brooks S, Makvandi-Nejad S, Chu E, Allen J, Streeter C, Gu E, McCleery B, Murphy B, Bellone R, Sutter N. Morphological variation in the horse: defining complex traits of body size and shape. Anim Genet. 2010;41(s2): 159-65.

6. Herre W, Röhrs M. Haustiere-zoologisch gesehen. Berlin: Springer-Verlag; 2013.

7. Darwin C. The variation of animals and plants under domestication. London: J. Murray; 1868.

8. Sánchez-Villagra MR, Segura V, Geiger M, Heck L, Veitschegger K, Flores D. On the lack of a universal pattern associated with mammalian domestication - differences in skull growth trajectories across phylogeny. Roy Soc Open Sci. 2017;4(10):170876.

9. Drake AG, Klingenberg CP. Large-scale diversification of skull shape in domestic dogs: disparity and modularity. Am Nat. 2010;175(3):289-301.

10. Veitschegger K. Life history evolution in extant and extinct Laurasiatheria case studies elucidating the junctions among selective forces, disparity, and trait evolution. University of Zurich; 2017.

11. Young NM, Linde-Medina M, Fondon JW, Hallgrímsson B, Marcucio RS Craniofacial diversification in the domestic pigeon and the evolution of the avian skull. Nat Ecol Evol. 2017;1:0095.

12. Evin A, Cucchi T, Cardini A, Vidarsdottir US, Larson G, Dobney K. The long and winding road: identifying pig domestication through molar size and shape. J Archaeol Sci. 2013;40(1):735-43.

13. Evin A, Flink LG, Bălășescu A, Popovici D, Andreescu R, Bailey D, Mirea P, Lazăr C, Boroneanț A, Bonsall C. Unravelling the complexity of domestication: a case study using morphometrics and ancient DNA analyses of archaeological pigs from Romania. Phil Trans R Soc B. 2015:370(1660):20130616.

14. Seetah K, Cardini A, Barker G. A 'long-fuse domestication'of the horse? Tooth shape suggests explosive change in modern breeds compared with extinct populations and living Przewalski's horses. The Holocene. 2016;26(8): 1326-33.

15. Ameen C, Hulme-Beaman A, Evin A, Germonpré M, Britton K, Cucchi T, Larson G, Dobney K. A landmark-based approach for assessing the reliability of mandibular tooth crowding as a marker of dog domestication. J Archaeol Sci. 2017;85:41-50.

16. Cucchi T, Mohaseb A, Peigné S, Debue K, Orlando L, Mashkour M. Detecting taxonomic and phylogenetic signals in equid cheek teeth: towards new palaeontological and archaeological proxies. Royal Society Open Sci. 2017; 4(4):160997

17. Simon H. The architecture of complexity. Proc Am Philos Soc. 1962;106(6): 467-82.

18. Bolker JA. Modularity in development and why it matters to evo-devo. Amercian Zoologist. 2000;40(5):770-6

19. Callebaut W, Rasskin-Gutman D. Modularity: understanding the development and evolution of natural complex systems. Cambridge: MIT press; 2005.

20. Goswami A. Cranial modularity shifts during mammalian evolution. Am Nat. 2006;168(2):270-80.

21. Goswami A. Cranial modularity and sequence heterochrony in mammals. Evol Dev. 2007:9(3):290-8.

22. Goswami A, Finarelli JA. EMMLi: a maximum likelihood approach to the analysis of modularity. Evolution. 2016;70(7):1622-37.

23. Hallgrímsson B, Jamniczky H, Young NM, Rolian C, Parsons TE, Boughner JC, Marcucio RS. Deciphering the palimpsest: studying the relationship between morphological integration and phenotypic covariation. Evol Biol. 2009;36(4):355-76

24. Klingenberg CP. Evolution and development of shape: integrating quantitative approaches. Nat Rev Genet. 2010;1 1(9):623.

25. Pigliucci M. Is evolvability evolvable? Nat Rev Genet. 2008;9(1):75.

26. Wagner GP, Pavlicev M, Cheverud JM. The road to modularity. Nat Rev Genet. 2007:8(12):921.

27. Hendrikse JL, Parsons TE, Hallgrímsson B. Evolvability as the proper focus of evolutionary developmental biology. Evol Dev. 2007:9(4):393-401.

28. Goswami A, Polly PD. The influence of modularity on cranial morphological disparity in Carnivora and Primates (Mammalia). PLoS One. 2010;5(3):e9517.

29. Wilson LA. The contribution of developmental palaeontology to extensions of evolutionary theory. Acta Zool. 2013;94(3):254-60.

30. Klingenberg CP. Cranial integration and modularity: insights into evolution and development from morphometric data. Hystrix, the Italian J of Mammalogy. 2013;24(1):43-58.

31. Porto A, de Oliveira FB, Shirai LT, De Conto V, Marroig G. The evolution of modularity in the mammalian skull I: morphological integration patterns and magnitudes. Evol Biol. 2009;36(1):118-35.

32. Marroig G, Shirai LT, Porto A, de Oliveira FB, De Conto V. The evolution of modularity in the mammalian skull II: evolutionary consequences. Evol Biol. 2009;36(1):136-48

33. Koyabu D, Werneburg I, Morimoto N, Zollikofer CP. Forasiepi AM, Endo H, Kimura J, Ohdachi SD, Son NT, Sánchez-Villagra MR. Mammalian skull heterochrony reveals modular evolution and a link between cranial development and brain size. Nat Commun. 2014;5:3625.

34. MacFadden BJ. Fossil horses: systematics, paleobiology, and evolution of the family Equidae. Cambridge: Cambridge University Press; 2008.

35. Radinsky L. Allometry and reorganization in horse skull proportions. Science. 1983:221(4616):1189-91.

36. Radinsky L. Ontogeny and phylogeny in horse skull evolution. Evolution 1984:38(1):1-15.

37. Vilstrup JT, Seguin-Orlando A, Stiller M, Ginolhac A, Raghavan M, Nielsen SC, Weinstock J, Froese D, Vasiliev SK, Ovodov ND. Mitochondrial phylogenomics of modern and ancient equids. PLoS One. 2013:8(2):e55950.

38. Bennett DK. Stripes do not a zebra make, part I: a cladistic analysis of Equus. Syst Biol. 1980;29(3):272-87.

39. Hanot P, Guintard C, Lepetz S, Cornette R. Identifying domestic horses, donkeys and hybrids from archaeological deposits: a 3D morphological investigation on skeletons. J Archaeol Sci. 2017;78:88-98. 
40. Beldade P, Koops K, Brakefield PM. Modularity, individuality, and evo-devo in butterfly wings. Proc Natl Acad Sci. 2002;99(22):14262-7.

41. Young NM, Hallgrímsson B. Serial homology and the evolution of mammalian limb covariation structure. Evolution. 2005:59(12):2691-704.

42. Bolstad GH, Hansen TF, Pélabon C, Falahati-Anbaran M, Pérez-Barrales R, Armbruster WS. Genetic constraints predict evolutionary divergence in Dalechampia blossoms. Phil Trans R Soc B. 2014;369(1649):20130255.

43. Melo D, Porto A, Cheverud JM, Marroig G. Modularity: genes, development, and evolution. Annu Rev Ecol Evol Syst. 2016;47:463-86.

44. Curth S, Fischer MS, Kupczik K. Patterns of integration in the canine skull: an inside view into the relationship of the skull modules of domestic dogs and wolves. Zoology. 2017;125:1-9.

45. Parr WC, Wilson LA, Wroe S, Colman NJ, Crowther MS, Letnic M. Cranial shape and the modularity of hybridization in dingoes and dogs; hybridization does not spell the end for native morphology. Evol Biol. 2016; 43(2):171-87.

46. Goswami A, Smaers J, Soligo C, Polly P. The macroevolutionary consequences of phenotypic integration: from development to deep time. Phil Trans R Soc B. 2014;369(1649):20130254.

47. Rohlf FJ, Bookstein FL. Roceedings of the Michigan morphometrics workshop. Michigan: University of Michigan Museum of Zoology; 1990.

48. Seetah K, Cucchi T, Dobney K, Barker G. A geometric morphometric re-evaluation of the use of dental form to explore differences in horse (Equus caballus) populations and its potential zooarchaeological application. J Archaeol Sci. 2014;41:904-10.

49. Rohlf F. tpsDig2, version 2.30. 2015. http://life.bio.sunysb.edu/morph. Accessed 15 Sept 2017.

50. Rohlf FJ, Slice D. Extensions of the Procrustes method for the optimal superimposition of landmarks. Syst Biol. 1990;39(1):40-59.

51. Kolamunnage R, Kent JT. Principal component analysis for shape variation about an underlying symmetric shape. Stochastic geometry, biological structure and images. 2003:137-9.

52. Adams DC, Collyer ML, Kaliontzopoulou A, Sherratt E: GEomorph: software for geometric morphometric analyses. R package version 3.0.5. 2017.

53. Price M. Pigs and power: pig husbandry in northern Mesopotamia during the emergence of social complexity (6500-2000 BC). 2016.

54. Zelditch ML, Swiderski DL, Sheets HD. Geometric Morphometrics for biologists: a primer. Cambridge: Academic Press; 2012.

55. Foote M. Contributions of individual taxa to overall morphological disparity. Paleobiology. 1993;19(4):403-19.

56. Team RDC. R: a language and environment for statistical computing. In. Vienna: R Foundation for Statistical Computing; 2017.

57. Baylac M: Rmorph: A R geometric and multivariate morphometrics library. 2012.

58. Schlager S. Morpho and Rvcg-shape analysis in R. Statistical Shape and Deformation Analysis: Methods, Implementation and Applications. 2017;217: 217-56

59. Cheverud JM. Phenotypic, genetic, and environmental morphological integration in the cranium. Evolution. 1982;36(3):499-516.

60. Reeve E, Murray P. Evolution in the horse's skull. Nature. 1942;150(3805): 402-3.

61. Cabrera JM, Giri F. Evomorph: evolutionary morphometric simulation, R package version 0.9. 2016.

62. Pavlicev M, Wagner GP, Cheverud JM. Measuring evolutionary constraints through the dimensionality of the phenotype: adjusted bootstrap method to estimate rank of phenotypic covariance matrices. Evol Biol. 2009;36(3): 339-53.

63. Evans, K. E., and P. D. McGreevy. "Conformation of the equine skull: A morphometric study." Anatomia, histologia, embryologia 35.4 (2006): 221-227.

64. Zhu, L., Shi, X., Wang, J., and Chen, J.. "A morphometric study on the skull of donkey (Equus asinus)." International Journal of Morphology 32.4 (2014): 1306-1310.

65. Eisenmann, Véra, and Michel Baylac. "Extant and fossil Equus (Mammalia, Perissodactyla) skulls: a morphometric definition of the subgenus Equus." Zoologica Scripta 29.2 (2000): 89-100.

\section{Submit your next manuscript to BioMed Central and we will help you at every step:}

- We accept pre-submission inquiries

- Our selector tool helps you to find the most relevant journal

- We provide round the clock customer support

- Convenient online submission

- Thorough peer review

- Inclusion in PubMed and all major indexing services

- Maximum visibility for your research

Submit your manuscript at www.biomedcentral.com/submit
Biomed Central 